\title{
Testosterone up. A case of disease mongering?
}

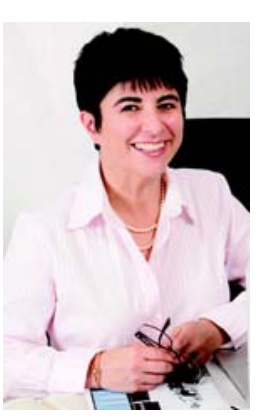

Annette Katelaris Editor akatelaris@mja.com.au doi: 10.5694/mjal2.c0604 $\mathrm{n}$ this issue, Handelsman (page 642) describes changes in the patterns of testosterone prescribing in Australia from 1992 to 2010. He reports that there has been at least a twofold increase in total expenditure on prescriptions, taking into account inflation and population growth, and the increase in expenditure is greater than the increase in prescribing. Yet, there has been no change in the approved indications for the use of testosterone (androgen deficiency due to disorders of the hypothalamic-pituitary-testicular axis) or in the frequency of the conditions for which it is approved.

Rather, following the lead of Europe and the United States, much of the recent increase in testosterone prescribing appears to be for conditions such as male sexual dysfunction and the "andropause". There is debate about the validity of the andropause as a concept (let alone its diagnosis), and testosterone deficiency is a rare cause of male sexual dysfunction. One suspects a strong marketing campaign has led to the overuse of testosterone as a tonic for male sexual dysfunction and ageing, without proper evidence.

The risks inherent in this situation are clear. Testosterone is known to have significant adverse effects, such as unfavourable cardiovascular outcomes and a possible effect on the progression of subclinical prostate cancer. One recalls the overblown hopes for hormone replacement therapy in women and wonders about an ethical lapse allowing similar mistakes to be repeated for men.

In a related article, Vitry and Mintzes (page 619) discuss the regulatory failures that have allowed the above situation to arise and call for change. They describe the techniques used by pharmaceutical companies to subvert the regulations that ban direct-to-consumer advertising. This is banned throughout the industrialised world, except in the US and New Zealand. Disease-awareness campaigns are one way that drug companies can increase prescribing rates for their products. Another is the "help seeking" campaign. In the case of testosterone, the authors describe a campaign that showed a frustrated 30- or 40something-year-old couple in bed, asking: "Has he lost that loving feeling?" The campaign's suggestion is to see your doctor; its implication is that he or she will prescribe a medicine that will right the situation.

Both these articles raise the concept of disease mongering, which was described two decades ago. ${ }^{1} \mathrm{By}$ "medicalising" normality and expanding the boundaries of treatable illness, and therefore the number of potential patients, many groups, not least pharmaceutical companies and medical practitioners, stand to benefit. But there may be considerable costs - the risk of iatrogenic illness, the waste of limited resources, and the diversion of resources from the treatment of more important diseases.

There needs to be reasonable evidence to investigate and treat patients. We need to be vigilant against pharmaceutical industry pressure, both overt and covert, and discourage single-issue clinics that push this agenda.

Also in this issue is important research about the current state of hepatitis C treatment in Australia. Gidding and colleagues (page 633) show that current treatments in a real, non-trial setting deliver very significant benefits (including for those typically excluded from trial settings). Hellard and colleagues (page 638) model the effects of targeting delivery of treatments for hepatitis $\mathrm{C}$ infection among people who inject drugs, and predict a potentially large decrease in prevalence.

Dore (page 629) provides an overview of future treatments for hepatitis $C$, treatments which promise to change the way hepatitis is treated by offering greater efficacy and accessibility — not to be missed by those managing the disease.

1 Payer L. Disease-mongers: how doctors, drug companies, and insurers are making you feel sick. New York: Wiley and Sons, 1992: 292.

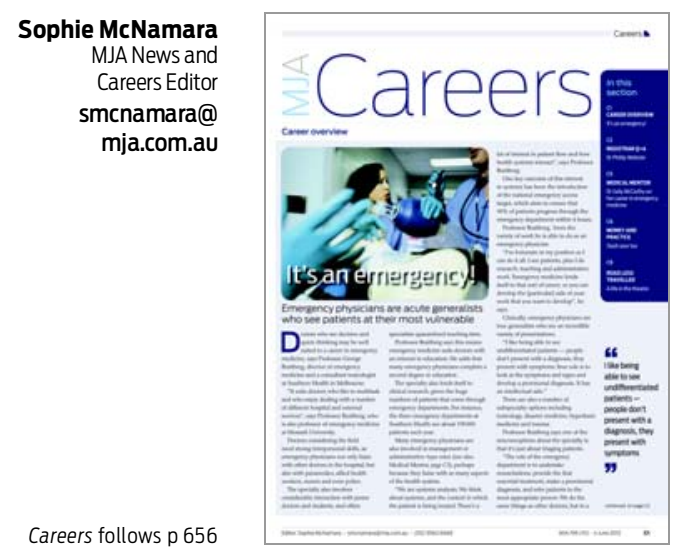

\section{Surgeon hits centre stage}

While most doctors are familiar with the operating theatre, in this issue of MJA Careers we talk to a doctor who has found success in another type of theatre, as a playwright (page C6). Dr Mohamed Khadra, a professor of surgery at the University of Sydney, has co-written a play with acclaimed playwright David Williamson. The play, At any cost?, draws on Dr Khadra's medical experience as it discusses the decisions families make as the end of life looms. Also in this issue of MJA Careers, we talk to several emergency medicine physicians about what drew them to the high-pressure world of the emergency department (page C1). For many, it is the combination of a truly generalist career and a satisfying worklife balance that makes the specialty so appealing. 